\title{
Seleção em populações mutantes de feijão (Phaseolus vulgaris L.) para caracteres adaptativos
}

\author{
Fabiani da Rocha \\ Leiri Daiane Barili \\ Soraya Helena Garcia \\ Ricardo Modena \\ Jefferson Luís Meirelles Coimbra* \\ Altamir Frederico Guidolin \\ Juliano Garcia Bertoldo \\ Universidade do Estado de Santa Catarina, Centro de Ciências Agroveterinárias \\ Instituto de Melhoramento e Genética Molecular (IMEGEM) \\ Av. Camões 2090, CEP 88520-000, Lages - SC, Brasil \\ *Autor para correspondência \\ coimbrajefferson@cav.udesc.br
}

\section{Resumo}

A existência de variabilidade é fundamental para o sucesso do melhoramento. As cultivares comerciais de feijão possuem pouca variabilidade para caracteres adaptativos. O uso de agentes mutagênicos pode incrementar a freqüência de mutação, possibilitando o desenvolvimento de variação para as características de interesse. Assim, quatro genótipos de feijão foram submetidos a raios gama provenientes de ${ }^{60} \mathrm{Co}$, nas doses de 0,100 , 200 e 400Gy, em 2006/07. Na safra seguinte (2007/08) as populações mutantes submetidas às doses de 0,100 e $200 \mathrm{~Gy}$, foram cultivadas num delineamento em blocos aumentados. A avaliação das famílias mutantes e não mutantes revelou significativa dissimilaridade fenotípica. Pela estimativa da distância de Mahalanobis $\left(\mathrm{D}^{2}\right)$ foi possível formar quatro grupos, indicando a possibilidade de selecionar famílias segregantes promissoras para diâmetro de caule, estatura de planta e inserção do primeiro legume, sem alterar expressivamente os caracteres que compõem o rendimento de grãos.

Unitermos: Phaseolus vulgaris L., melhoramento de plantas, divergência genética, indução de mutação

\section{Abstract}

Selection in bean (Phaseolus vulgaris L.) mutant populations for adaptative characters. The existence of variability is primary to success in plant breeding. The commercial bean cultivars have a narrow variability for adaptive traits. However, the use of mutagenic agents can increase the mutation frequency, allowing the development of genetic variability in useful traits. Thus, four bean genotypes were submitted to gamma rays from ${ }^{60} \mathrm{Co}$, at doses of 0, 100, 200 and $400 \mathrm{~Gy}$ in the 2006/07 crop season. In the following crop season (2007/08) the 
mutant populations, submitted to doses of 0, 100 and 200Gy, were cultivated in a design of augmented blocks. The assessment of mutant and nonmutant families evidenced phenotypic divergence between families. From the Mahalanobis distance it was possible to distinguish four groups, indicating the possibility of selecting promising segregant families for stem diameter, plant height and height insertion of the first legume, without significantly changing grain-yield-related traits.

Key words: Phaseolus vulgaris L., plant breeding, genetic divergence, inducted mutation

\section{Introdução}

As cultivares de feijão (Phaseolus vulgaris L.) disponíveis no mercado são uniformes, principalmente quanto aos caracteres adaptativos e de importância agronômica, como por exemplo: inserção do primeiro legume, ciclo, diâmetro e estatura de planta. O estreitamento da base genética entre as cultivares de feijão reduz drasticamente a possibilidade de obter diferentes constituições genéticas nas gerações segregantes (Coimbra et al., 2004).

Mutações induzidas são definidas como alterações herdáveis de ordem qualitativa e quantitativa de DNA, não derivadas de segregação genética ou recombinação. Como a taxa de mutação espontânea é muito baixa, a indução de mutações tem sido utilizada para elevar a freqüência de alelos novos, tanto por agentes mutagênicos químicos, como as substâncias alquilantes (etilmetanossulfonato), quanto por agentes mutagênicos físicos, como as radiações ionizantes (Predieri, 2001). Alterações no DNA nuclear ou citoplasmático resultam em mutações gênicas e cromossômicas, gerando variabilidade genética, cuja limitação é a não especificidade da característica mutada (Tulmann Neto e Latado, 1997).

Nas últimas quatro décadas foram criadas aproximadamente 2250 cultivares de diferentes espécies oriundas do uso de agentes mutagênicos, impactando significativamente tanto na área cultivada quanto na economia mundial. A principal estratégia para o uso da mutação no melhoramento é obter ganho para uma ou duas características de maior interesse, sem alterar demasiadamente características de importância agronômica como, por exemplo, rendimento de grãos (Ahloowalia et al., 2004).
Sendo assim, o presente trabalho teve como objetivo avaliar a variabilidade genética entre as populações mutantes e selecionar populações segregantes $M_{2}$ com valores métricos superiores para os caracteres adaptativos: diâmetro de caule, estatura de planta e inserção do primeiro legume, sem alterar significativamente os caracteres primários que compõem o rendimento de grãos, como, por exemplo, o número de grãos por legume e o número de legumes por planta.

\section{Material e Métodos}

O trabalho foi desenvolvido nos anos agrícolas de 2006/07 e 2007/08 a campo em Lages, SC. Na primeira safra $(2006 / 07)$ aproximadamente 2000 sementes de quatro cultivares de feijão (Pérola, Iapar 81, IPR Uirapuru e IPR Chopim) foram tratadas com agente mutagênico físico (raios gama, provenientes de ${ }^{60} \mathrm{Co}$ ) que deram origem a geração $\mathrm{M}_{1}$. Sendo que, as doses totais irradiadas e absorvidas foram $0,100,200$ e 400Gy por tratamento, do agente mutagênico físico. As sementes da geração $M_{1}$ foram semeadas a campo na safra de 2006/07, sendo cada genótipo cultivado separadamente utilizando um delineamento de blocos ao acaso.

As sementes das populações mutantes $\left(\mathrm{M}_{2}\right)$ foram cultivadas na safra de 2007/08, a campo, num delineamento experimental de blocos aumentados. As observações fenotípicas para as famílias mutantes foram realizadas individualmente para cada planta em todos os tratamentos.

A equação do modelo estatístico multivariado tem a mesma expressão da equação para a situação univariada, sendo os termos escalares substituídos por vetores, onde cada um dos termos é um vetor de dimensão " $v$ " cujos elementos são identificados pelo mesmo símbolo do 
fator com acréscimo de um " $j$ " subscrito para identificar a correspondente variável resposta, onde: $Y_{i k l}=m+$ $a_{k}+b_{1}+a b_{k l}+e_{i k l}$, $m$ é a média geral esperada, $a_{k}$ é o efeito diferencial do nível $i$ do fator $A, b_{l}$ é o efeito diferencial do nível 1 do fator $B, a b_{k l}$ é o efeito diferencial da interação do $k$-ésimo nível do fator $A$ com o $l$-ésimo nível do fator $B$, e $e_{i k l}$ é o erro experimental.

Para realização da análise de variância multivariada (MANOVA) e posterior análise dos contrastes previamente estabelecidos, foram avaliadas seis variáveis respostas: $i$ ) diâmetro do caule $(\mathrm{cm}), i i)$ estatura de planta $(\mathrm{cm})$, iii) inserção do primeiro legume $(\mathrm{cm})$, iv) número de grãos por legume, v) número de legumes por planta e vi) comprimento do legume (cm).

Os contrastes entre os vetores médios na situação multivariada podem ser definidos como: $\delta=c_{1} \mu_{1}+$ $c_{2} \mu_{2}+\ldots c_{k} \mu_{2}$, onde foram avaliados da seguinte forma: $H_{0}: c=0, H_{A}: c \neq 0$, onde $c$ é uma combinação linear dos vetores de médias $\mu_{1}, \mu_{2}, \ldots$, ou $c=c_{1} \mu_{1}+c_{2} \mu_{2}+$ $\ldots c_{t} \mu_{t}, \mathrm{e} c_{l}, c_{2}, \ldots, c_{t}$ são escalares constantes tais que: $c_{1}+c_{2}+\ldots+c_{t}=0$. Um estimador não viesado de $\delta$ é dado pelo correspondente vetor médio da amostra: ' $\delta=c_{1} y_{1}+c_{2} y_{2}+\ldots c_{k} y_{k}$ (Rencher, 2002). Os contrastes não ortogonais multivariados foram previamente definidos, sabendo-se que os genótipos do grupo carioca são Pérola e Iapar 81, e do grupo preto IPR Uirapuru e IPR Chopim, como sendo: $\mathrm{C}_{1}$ : média dos genótipos carioca $\mathrm{x}$ média do genótipo Pérola submetido à dose de $100 \mathrm{~Gy} ; \mathrm{C}_{2}$ : média dos genótipos carioca $\mathrm{x}$ média do genótipo Iapar 81 submetido à dose de $100 \mathrm{~Gy} ; \mathrm{C}_{3}$ : média dos genótipos preto $\mathrm{x}$ média do genótipo IPR Uirapuru submetido à dose de $100 \mathrm{~Gy}$; $\mathrm{C}_{4}$ : média dos genótipos preto $\mathrm{x}$ média do genótipo IPR Chopim submetido à dose de $100 \mathrm{~Gy} ; \mathrm{C}_{5}$ : média dos genótipos carioca $\mathrm{x}$ média do genótipo Pérola submetido à dose de $200 \mathrm{~Gy} ; \mathrm{C}_{6}$ : média dos genótipos carioca x média do genótipo Iapar 81 submetido à dose de 200Gy; $\mathrm{C}_{7}$ : média dos genótipos preto $\mathrm{x}$ média do genótipo IPR Uirapuru submetido à dose de 200Gy e $\mathrm{C}_{8}$ : média dos genótipos preto $\mathrm{x}$ média do genótipo IPR Chopim submetido à dose de 200Gy. Todos os dados foram analisados por meio do procedimento GLM opção MANOVA do sistema estatístico $\mathrm{SAS}^{\circledR}$ 9.1.3 (2007).

\section{Resultados e Discussão}

Não alcançou-se sucesso com a utilização da dose de 400Gy na geração $M_{1}$, uma vez que não houve germinação de plântulas (dose letal para espécie diplóide, como o feijão), assim, não se obteve populações mutantes $\mathrm{M}_{2}$ provenientes desta dose. Portanto, os resultados dissertam somente para as famílias mutantes provenientes das doses de 100 e 200Gy.

Os dados incluídos na Tabela 1 revelam que tanto o fator de tratamento qualitativo (genótipos) quanto o fator quantitativo (doses do agente mutagênico físico raios gama) não podem ser analisados separadamente, pois evidenciaram uma forte influência diferencial dos genótipos quando submetidos às doses de radiação gama $\left({ }^{60} \mathrm{Co}\right)$, de modo que, as doses avaliadas deste agente mutagênico foram eficientes na alteração da magnitude da variabilidade genética, quantificada e avaliada por meio de análise de variância multivariada (MANOVA), que pode fornecer uma informação precisa a respeito dos caracteres e do grau de divergência genética envolvido em cada população testada, por meio das estimativas da média e da variância, comparando sempre em relação aos genótipos não irradiados (testemunhas).

Assim sendo, o agente mutagênico induziu modificações significativas entre as populações avaliadas. Gregory (1967) e Chandhanamutta e Frey (1974) consideraram que a alteração da média das populações tratadas com mutagênico indica a ocorrência de modificações num pequeno número de genes de grande expressão no caráter denominado macromutação; no entanto, o efeito num grande número de genes de pequena expressão sobre o fenótipo, resulta na alteração de variância, que originalmente foi chamado de micromutações. De modo geral, pode ser observada uma grande predominância da macromutação em relação à micromutação independente das doses avaliadas do agente mutagênico, da constituição genética e do tipo de grão (preto ou carioca). 
TABELA 1: Resumo da análise de variância multivariada, por meio de quatro testes estatísticos, indicando a probabilidade para o teste $F$ para seis variáveis respostas avaliadas simultaneamente, com dois fatores de tratamento: $i)$ genótipo (com 4 níveis); e ii) dose (com 3 níveis). Lages/SC, 2008.

\begin{tabular}{clrrr}
\hline Efeito & Teste estatístico & Valor & Valor $\mathbf{F}$ & Pr $>\mathbf{F}$ \\
\hline \multirow{4}{*}{$\begin{array}{c}\text { Genótipos } \\
\text { (G) }\end{array}$} & Lambda de Wilks & 0,43 & 7,34 & 0,0001 \\
& Pillai's Trace & 0,65 & 6,26 & 0,0001 \\
& Hotelling-Lawley & 1,14 & 8,49 & 0,0001 \\
& Roy's Greatest Root & 0,97 & 22,21 & 0,0001 \\
& Lambda de Wilks & 0,77 & 3,14 & 0,0001 \\
Doses (D) & Pillai's Trace & 0,24 & 2,97 & 0,0001 \\
& Hotelling-Lawley & 0,3 & 3,31 & 0,0001 \\
& Roy's Greatest Root & 0,29 & 6,47 & 0,0001 \\
\hline \multirow{4}{*}{$*$ D } & Lambda de Wilks & 0,44 & 3,41 & 0,0001 \\
& Pillai's Trace & 0,72 & 3,09 & 0,0001 \\
& Hotelling-Lawley & 0,98 & 3,63 & 0,0001 \\
& Roy's Greatest Root & 0,45 & 10,43 & 0,0001 \\
\hline
\end{tabular}

1/ $\mathrm{H}_{0}: \mu_{1}=\mu_{2}=\ldots=\mu_{\mathrm{k}}, \mathrm{H}_{\mathrm{A}}: \mu_{1} \neq \mu_{2} \neq \ldots \neq \mu_{\mathrm{k}}$

\section{Análise da variância multivariada}

Uma tarefa fundamental em muitas análises estatísticas é caracterizar a direção e a magnitude da variabilidade de uma série de dados, sendo que, uma análise mais profunda dos dados inclui estimativas da média populacional e a da variância (Coimbra, 2004). Este tipo de informação é ferramenta indispensável para o melhoramento de plantas, pois a variância aditiva (ausência de dominância) é a variância dos valores genéticos, sendo este o componente mais importante, uma vez que é a principal causa de semelhança entre parentes e, por conseguinte, o principal determinante das propriedades genéticas da população e da resposta da população à seleção (Falconer e Mackay, 1996).

Oresultado obtido pela verificação da homogeneidade da matriz de covariância por meio da estatística de verossimilhança generalizada $\left(\chi^{2}=439,34 ; \mathrm{GL}=315\right.$ e; $\left.\operatorname{Pr}>\chi^{2}=0,001\right)$ justifica o procedimento de testes para situação da matriz de covariância heterogênea.
Os resultados da Tabela 1 apresentaram diferenças significativas $(\operatorname{Pr}<0,01)$ para todos os efeitos principais avaliados (genótipos e doses) e para o efeito da interação genótipos $\mathrm{x}$ doses. Este fato revela a existência de variabilidade entre os genótipos estudados (Sudré et al., 2005), indicando um comportamento diferenciado entre os genótipos avaliados frente às doses de raios gama.

Normalmente, podem ser observados incrementos no número de mutantes com o aumento da dose e aumento dos efeitos letais (Coimbra et al., 2004). Assim, na Tabela 2 pode ser observada a alteração ocorrida nos genótipos em função das doses avaliadas. Para o caráter diâmetro do caule as variações não se mostram tão expressivas, porém, no que tange a estatura de planta é possível que seja observada uma vasta modificação, tanto de forma positiva quanto negativa, com destaque para os genótipos Pérola e Iapar 81 na dose 100Gy (mostraram aumento para a característica). Em relação à altura de inserção do primeiro legume, pode-se notar que o genótipo Pérola, em ambas as doses, apresentou expressivo desempenho, comportamento idêntico esse genótipo mostrou em relação ao comprimento do legume. Analisando-se o número de grãos por legume e o número de legume por planta o genótipo IPR Uirapuru merece destaque na dose 200Gy, já que o mesmo apresentou grande incremento para ambas as características, bem como o genótipo IPR Chopim na dose 100Gy para o caráter número de legumes por planta (incremento 10,10 legumes).

De acordo com estes resultados (Tabela 2) podese sugerir que o agente mutagênico físico foi eficiente na criação de novos alelos para todos os caracteres avaliados, corroborando assim, com a capacidade real dos raios gama em induzir mutações e, principalmente em provocar alterações consistentes nas freqüências alélicas e nas freqüências genotípicas do caráter. Coimbra et al. (2005a) avaliando o efeito do agente mutagênico físico raios gama $\left({ }^{60} \mathrm{Co}\right)$ em genótipos de aveia, obtiveram resultados similares, ou seja, verificaram um aumento de variabilidade em decorrência da irradiação com doses de raios gama, na ocasião o caráter avaliado foi estatura de planta. Essas alterações percebidas indicam que é possível obter variabilidade genética pelo emprego de agentes mutagênicos, sendo possível alterar uma ou mais características desejáveis, melhorando assim as cultivares já existentes e desenvolvendo novos genótipos (Maluszynski et al., 1998). 
TABELA 2: Média e desvio padrão (DP) das populações mutantes $\left(\mathrm{M}_{2}\right)$ de feijões avaliados por meio dos caracteres diâmetro do caule (Dc em $\mathrm{cm})$; estatura de planta $(\mathrm{Et} \mathrm{em} \mathrm{cm})$; inserção do primeiro legume (IL em $\mathrm{cm})$; número de grãos por legume $(\mathrm{GL})$; comprimento do primeiro legume $(\mathrm{CL}$ em $\mathrm{cm})$ e número de legumes por planta (LP). Lages, SC, 2008.

\begin{tabular}{lcccccccccccccc}
\hline \multirow{2}{*}{ Genótipo } & & \multicolumn{2}{c}{ Dc } & \multicolumn{2}{c}{ Et } & \multicolumn{2}{c}{ IL } & \multicolumn{2}{c}{ GL } & \multicolumn{2}{c}{ CL } & \multicolumn{2}{c}{ LP } \\
\cline { 2 - 12 } & Dose & Média & DP & Média & DP & Média & DP & Média & DP & Média & DP & Média & DP \\
\hline Pérola & 0 & 0,68 & 0,16 & 87,35 & 16,08 & 17,42 & 4,77 & 6,05 & 0,94 & 10,92 & 0,86 & 15,40 & 5,10 \\
Iapar 81 & 0 & 0,71 & 0,16 & 94,55 & 18,80 & 16,82 & 5,45 & 5,40 & 0,82 & 10,77 & 1,05 & 19,65 & 7,73 \\
IPR Uirapuru & 0 & 0,83 & 0,18 & 89,37 & 15,80 & 21,09 & 6,66 & 5,63 & 1,01 & 9,94 & 0,86 & 20,26 & 8,74 \\
IPR Chopim & 0 & 0,78 & 0,13 & 96,25 & 18,23 & 16,58 & 5,32 & 6,05 & 0,89 & 10,12 & 0,99 & 17,20 & 3,62 \\
Pérola & 100 & 0,57 & 0,06 & 96,80 & 20,77 & 20,91 & 10,60 & 4,80 & 0,63 & 11,27 & 1,51 & 13,30 & 3,77 \\
Iapar 81 & 100 & 0,70 & 0,24 & 101,00 & 23,50 & 14,17 & 2,79 & 5,30 & 0,67 & 10,96 & 0,90 & 27,30 & 7,79 \\
IPR Uirapuru & 100 & 0,81 & 0,15 & 84,90 & 5,93 & 18,80 & 6,34 & 5,70 & 0,95 & 9,89 & 0,95 & 13,30 & 3,77 \\
IPR Chopim & 100 & 0,79 & 0,07 & 91,80 & 25,34 & 21,60 & 8,34 & 6,10 & 0,88 & 10,08 & 0,93 & 27,30 & 7,79 \\
Pérola & 200 & 0,57 & 0,05 & 91,43 & 8,60 & 22,43 & 10,20 & 4,14 & 1,68 & 11,95 & 1,30 & 18,71 & 9,25 \\
Iapar 81 & 200 & 0,61 & 0,09 & 80,67 & 20,06 & 15,44 & 3,13 & 5,56 & 0,53 & 10,32 & 0,68 & 15,11 & 5,13 \\
IPR Uirapuru & 200 & 0,81 & 0,16 & 71,70 & 6,24 & 16,00 & 6,27 & 6,20 & 0,63 & 10,10 & 0,95 & 29,10 & 6,90 \\
IPR Chopim & 200 & 0,69 & 0,10 & 77,20 & 16,16 & 17,50 & 4,55 & 6,20 & 1,03 & 9,78 & 0,34 & 20,20 & 7,76 \\
\hline
\end{tabular}

A seleção de características que aumentem o rendimento da cultura, bem como que facilitem os tratos culturais, as operações mecanizadas envolvendo a colheita, é necessária, de modo que, é importante avaliar caracteres relacionados com a prática da colheita, como o diâmetro do caule, a estatura de planta e inserção do legume (Shimada et al., 2000), sem deixar de lado os componentes do rendimento, como o número de grãos por legume e o número de legumes por planta que estão diretamente relacionados ao rendimento de grãos, sendo que quanto maiores os seus valores, maior será o rendimento da cultura (Coimbra et al., 1999a). Assim, busca-se um equilíbrio entre as características, de forma que a planta tenha um ideótipo que maximize o rendimento de grãos, levando em consideração os demais caracteres associados ao rendimento, sendo de suma importância num programa de melhoramento balancear a característica objetivada com as demais características associadas, como por exemplo, um aumento expressivo do número de legumes pode não ser suportado por uma planta que não apresentar incremento no diâmetro do caule.

As duas primeiras variáveis canônicas $\left(\mathrm{VC}_{\mathrm{i}}\right)$ são suficientes para explicar $90 \%$ da variação total contida no conjunto de características analisadas (Tabela 3). De acordo com Cruz e Regazzi (2001) se as duas primeiras variáveis canônicas conseguem explicar acima de $80 \%$ da variação total encontrada, pode se obter uma interpretação satisfatória da variabilidade entre genótipos. 
TABELA 3: Autovalores $\left(\lambda_{\mathrm{i}}\right)$ e variação percentual correspondente, explicada pelas variáveis canônicas $\left(\mathrm{VC}_{\mathrm{i}}\right)$ e coeficientes canônicos padronizados (autovetores) de seis caracteres ( $\mathrm{Dc}=$ diâmetro do caule em $\mathrm{cm} ; \mathrm{Et}=$ estatura de planta em $\mathrm{cm} ; \mathrm{IL}$ = inserção do primeiro legume em $\mathrm{cm} ; \mathrm{GL}=$ número de grãos por legume; $\mathrm{CL}=$ comprimento do primeiro legume em $\mathrm{cm}$; e $\mathrm{LP}=$ número de legumes por planta) avaliados em oito populações de feijão (4 e 8 populações fixas e segregantes $\left(\mathrm{M}_{2}\right)$, respectivamente). Lages/SC, 2008.

\begin{tabular}{|c|c|c|c|c|c|c|c|c|c|}
\hline & \multirow[b]{2}{*}{$\mathbf{V C}_{\mathrm{i}}$} & \multicolumn{2}{|c|}{ Autovalores } & \multicolumn{6}{|c|}{ Coeficientes canônicos padronizados } \\
\hline & & $\lambda_{\mathrm{i}}$ & $\begin{array}{c}\text { Acumulado } \\
(\%)\end{array}$ & Dc & Et & IL & GL & CL & LP \\
\hline \multirow{3}{*}{ Genótipo (G) } & $\mathrm{VC}_{1}$ & ${ }^{*} 0,97$ & 0,85 & 0,53 & $-0,29$ & $-0,17$ & 0,65 & $-0,76$ & 0,20 \\
\hline & $\mathrm{VC}_{2}$ & ${ }^{*} 0,12$ & 0,97 & $-0,58$ & 0,46 & $-0,69$ & 0,30 & $-0,08$ & 0,60 \\
\hline & $\mathrm{VC}_{3}$ & 0,04 & 1,00 & $-0,58$ & 0,37 & 0,57 & 0,60 & $-0,23$ & $-0,02$ \\
\hline \multirow{2}{*}{ Dose (D) } & $\mathrm{VC}_{1}$ & ${ }^{*} 0,29$ & 0,97 & 0,66 & 0,94 & $-0,02$ & 0,10 & 0,14 & $-0,54$ \\
\hline & $\mathrm{VC}_{2}$ & 0,01 & 1,00 & 0,61 & $-0,40$ & $-0,53$ & 0,82 & 0,18 & $-0,38$ \\
\hline \multirow{6}{*}{$G * D$} & $\mathrm{VC}_{1}$ & ${ }^{*} 0,45$ & 0,46 & $-0,30$ & 0,26 & 0,50 & $-0,85$ & 0,44 & 0,64 \\
\hline & $\mathrm{VC}_{2}$ & ${ }^{*} 0,43$ & 0,90 & $-0,12$ & $-0,28$ & $-0,20$ & 0,47 & $-0,14$ & 1,10 \\
\hline & $\mathrm{VC}_{3}$ & 0,07 & 0,98 & 0,26 & 0,48 & $-0,84$ & $-0,04$ & 0,55 & $-0,14$ \\
\hline & $\mathrm{VC}_{4}$ & 0,02 & 1,00 & 1,03 & $-0,37$ & 0,22 & $-0,03$ & 0,51 & $-0,26$ \\
\hline & $\mathrm{VC}_{5}$ & 0,00 & 1,00 & 0,48 & 0,82 & 0,18 & 0,22 & $-0,45$ & $-0,07$ \\
\hline & $\mathrm{VC}_{6}$ & 0,00 & 1,00 & $-0,39$ & 0,31 & 0,26 & 0,64 & 0,59 & $-0,11$ \\
\hline
\end{tabular}

* significativo a $5 \%$ de probabilidade de erro pela estatística de teste da razão de verossimilhança.

Um dos grandes problemas do cultivo do feijão em grandes áreas está relacionado à dificuldade de mecanização da colheita, em razão de grandes perdas apresentadas. Essas perdas por sua vez ocorrem em razão da arquitetura de planta, as quais atualmente apresentam baixa altura de inserção dos legumes e suscetibilidade ao acamamento (Silva e Bevetori, 1994). Assim, apesar da diversidade constatada entre os genótipos, o foco deve ser apenas nos superiores em relação às características de maior interesse (Elias et al., 2007). Observando-se a Tabela 4, onde estão apresentados todos os contrastes, pode-se destacar dois, de acordo com as características objetivadas, sendo:

i) Sexto contraste (Iapar 81 na dose 200Gy): pois o mesmo mostrou incremento para o diâmetro do caule (0.48), estatura ( 0.80$)$, inserção de legume $(0.17)$ e número de legumes por planta (0.06). O aumento da altura de inserção do legume é tem uma função de suma importância, a fim de adaptar a cultura do feijão a colheita mecanizada (Alonço e Antunes, 1997). Da mesma forma que um aumento (ainda que pequeno) para o número de legumes por planta tem fundamental importância, visto que apresenta correlação alta e direta com rendimento de grãos (Ribeiro et al., 2004). Pode-se desta forma perceber a importância deste contraste ou desta família mutante uma vez que apresentou incremento nas características de interesse que preconizam a facilidade e a redução da perdas para colheita mecanizada, bem como um possível aumento do rendimento pelo incremento do número de legumes por planta;

ii) Oitavo contraste (IPR Chopim na dose 200Gy): apresentou incremento para a altura de inserção do primeiro legume $(0,13)$ o que vem a significar redução das perdas para a colheita mecanizada, concomitante com aumento para a estatu- 
ra de planta $(0,83)$, a qual é uma característica muito importante, já que Lins e Alves (2002), trabalhando com linhagens de feijão-mungo, encontraram correlação positiva entre estatura e rendimento de grãos, fato que deve ocorrer porque plantas mais baixas tendem a produzir menor número de flores/planta e conseqüentemente menor número de legumes por planta ou sementes por planta, ocasionando uma redução no rendimento de grãos. De forma a reduzir o acamamento, uma vez que é este o objetivo de programas de melhoramento de feijão (Carmo et al., 2007), facilitando a colheita mecanizada, esta família também se mostra promissora, apresentando um aumento para o caráter diâmetro do caule $(0,67)$.

Comparando-se a dose 100Gy a dose 200Gy (Tabela 4), pode-se observar que ocorreu um maior número de decréscimos para os valores das características estudadas na dose 100Gy. Esta situação pode ser explicada pelo fato de que menores doses causam menores efeitos sobre o genótipo e conseqüentemente sobre o fenótipo, e de acordo com esta análise resultados negativos reduzem o efeito da variável resposta em questão, ou seja, eles se aproximam mais dos valores das testemunhas (dose 0 ).

De acordo com os resultados encontrados nos contrastes, pode-se perceber a eficiência e a importância do uso de agentes mutagênicos na busca de variabilidade genética para plantas autógamas. É possível com o uso de agentes mutagênicos que se consiga incrementar determinadas características nas cultivares já existentes no mercado, facilitando e/ou acelerando o processo de seleção e lançamento de uma cultivar. Em famílias $\mathrm{M}_{4}$ de arroz, oriundas de sementes da cultivar BRS 7 - Taim irradiadas com ${ }^{60} \mathrm{Co}$, os autores Kopp et al. (2007) conseguiram obter variabilidade genética para o caráter tolerância a ácido butírico, mostrando a eficiência do uso do mesmo agente mutagênico e em planta autógama (arroz). Coimbra et al. (2005b) puderam concluir que o uso de agente mutagênico físico foi eficiente na criação de variabilidade para o caráter ciclo vegetativo em aveia, ou seja, o agente mutagênico físico possui eficiência na modificação do caráter, proporcionando assim um incremento no número de classes fenotípicas tanto para redução quanto para o aumento do número de dias entre a emergência e o florescimento.

TABELA 4: Teste multivariado dos efeitos simples: tratamento dentro de dose juntamente com o teste F para a comparação dos contrastes testados pela estatística de Wilks denominada de U, para os caracteres: $\mathrm{Dc}=$ diâmetro do caule em $\mathrm{cm} ; \mathrm{Et}=$ estatura de planta $\mathrm{em} \mathrm{cm} ; \mathrm{IL}=$ inserção do primeiro legume em $\mathrm{cm} ; \mathrm{GL}=$ número de grãos por legume; $\mathrm{CL}=$ comprimento do primeiro legume; e $\mathrm{LP}=$ número de legumes por planta. Lages/SC, 2008.

\begin{tabular}{|c|c|c|c|c|c|c|c|}
\hline \multirow{2}{*}{ Efeito $^{1}$} & \multirow[b]{2}{*}{$\operatorname{Pr}>\mathbf{F}$} & \multicolumn{6}{|c|}{ Coeficientes canônicos padronizados } \\
\hline & & Dc & $\mathbf{E t}$ & IL & GL & $\mathbf{C L}$ & $\mathbf{L P}$ \\
\hline $\mathrm{C}_{1}$ : Test vs. Pérola (100)_Carioca & 0,0075 & 0,69 & 0,14 & $-0,46$ & 0,73 & $-0,21$ & 0,23 \\
\hline $\mathrm{C}_{2}$ : Test vs. Iapar 81(100)_Carioca & 0,0027 & $-0,54$ & $-0,16$ & $-0,26$ & $-0,25$ & $-0,12$ & 1,19 \\
\hline $\mathrm{C}_{3}$ : Test vs. IPR Uirapuru (100)_Preto & 0,0446 & $-0,17$ & 0,77 & 0,10 & $-0,06$ & 0,27 & 0,75 \\
\hline $\mathrm{C}_{4}$ : Test vs. IPR Chopim(100)_Preto & 0,0098 & $-0,62$ & $-0,59$ & 0,24 & 0,19 & $-0,27$ & 1,09 \\
\hline $\mathrm{C}_{5}$ : Test vs. Pérola (200)_Carioca & 0,0001 & 0,57 & 0,28 & $-0,49$ & 0,90 & $-0,45$ & $-0,29$ \\
\hline $\mathrm{C}_{6}$ : Test vs. Iapar 81(200)_Carioca & 0,0141 & 0,48 & 0,80 & 0,17 & $-0,08$ & 0,54 & 0,06 \\
\hline $\mathrm{C}_{7}$ : Test vs. IPR Uirapuru (200)_Preto & 0,0001 & 0,33 & 0,87 & 0,19 & $-0,24$ & 0,18 & $-0,84$ \\
\hline $\mathrm{C}_{8}$ : Test vs. IPR Chopim (200)_Preto & 0,0002 & 0,67 & 0,83 & 0,13 & $-0,35$ & 0,38 & $-0,39$ \\
\hline
\end{tabular}

$\mathrm{U}=\frac{|E|}{|E+H|}$ 
Analisando a Figura 1, obtida através do agrupamento de Tocher, utilizando Mahalanobis como medida de distância, onde se tem a classificação de genótipos em grupos de similaridade, pode ser visualizada, com maior facilidade, a semelhança entre os mesmos, a formação de três grupos e a permanência de um genótipo isolado. Sendo que, um grupo foi formado pelos genótipos Pérola na dose 0, Iapar 81 na dose 200Gy, IPR Chopim na dose 0, IPR Uirapuru na dose 0 e IPR Uirapuru na dose 100Gy. No segundo grupo, permaneceram apenas genótipos carioca, em todas as doses $(0,100$ e $200 \mathrm{~Gy})$. No terceiro grupo ficaram Iapar 81 na dose $100 \mathrm{~Gy}$, IPR Uirapuru na dose 200Gy e Chopim na dose 100Gy. Isoladamente permaneceu o genótipo Chopim na dose 100Gy. O isolamento deste genótipo é um indicativo de sua maior dissimilaridade, por isso, pode ser considerado promissor para uso em futuro cruzamentos, se ao longo das gerações, manter a dissimilaridade e as características de interesse. A formação de grupos distintos corrobora com a existência de divergência genética entre as famílias mutantes nas doses avaliadas, o que vem a ser um aspecto positivo do ponto de vista que estas famílias podem ser conduzidas ou utilizados em hibridações artificiais com a finalidade de desenvolver variabilidade genética (Coimbra et al., 1999b). Vale ressaltar, porém, que alem de dissimilares, é necessário que os possíveis genitores associem média elevada e variabilidade para os caracteres que estão sendo melhorados (Bennin et al., 2002).

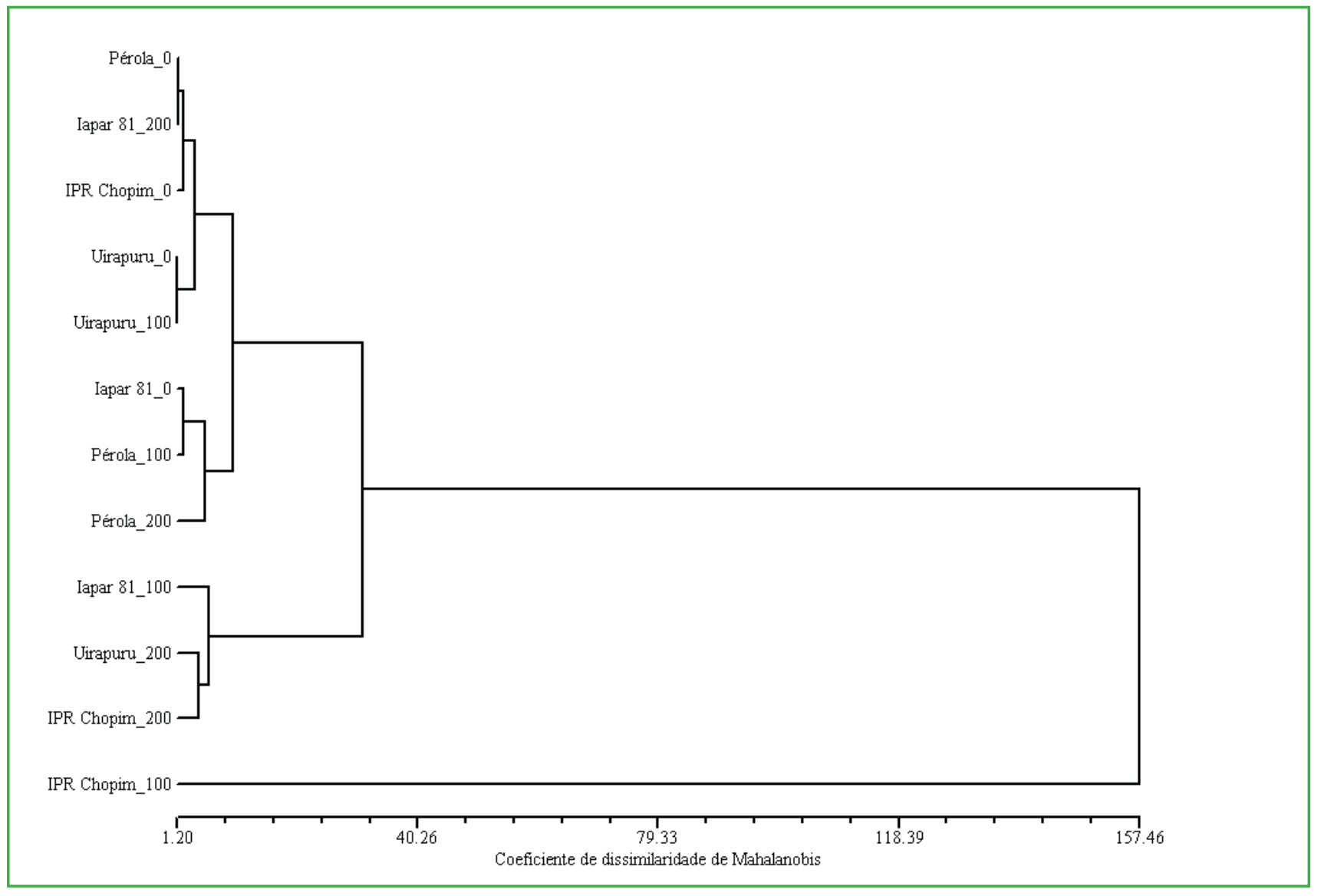

FIGURA 1: Dendrograma resultante da análise de quatro genótipos em três doses do agente mutagênico (0, 100 e 200 Gy), com base em seis caracteres, obtido pelo método do agrupamento de Tocher e utilizando a distância de Mahalanobis como medida da distância genética. Lages/SC, 2008. 
A partir dos resultados, foi possível concluir que existe divergência genética entre os genótipos avaliados, tanto entre como dentro de cada grupo (preto e carioca). Além disso, as famílias $\mathrm{M}_{2}$ apresentam caracteres promissores para uso direto e/ou para uso em hibridações.

\section{Referências}

Ahloowalia, B. S.; Maluszynski, M.; Nichterlein, K. 2004. Global impact of mutation-derived varieties. Euphytica, 135 (2): 187204.

Alonço, A. S.; Antunes, F. I. 1997. Semeadura direta de feijão em resteva de trigo, visando a colheita mecanizada direta. Pesquisa Agropecuária Brasileira, 32 (9): 919-922.

Bennin, G.; Carvalho, F. I. F.; Assmann, I. C.; Cigolini, J.; Cruz, P.; Marchioro, V.; Lorencetti, C.; Silva, J. A. G. 2002. Identificação da dissimilaridade genética entre genótipos de feijoeiro comum (Phaseolus vulgaris L.) do grupo preto. Revista Brasileira de Agrociência, 8 (3): 179-184.

Carmo, S. L. M.; Santos, J. B.; Hagiwara, W. E.; Ferreira, J. L. 2007. Avaliação do Stay Green em famílias segregantes de feijão (Phaseolus vulgaris L.). Ciências agrotécnicas, 31 (4): 953-957.

Chandhanamutta, P.; Frey, K. J. 1974. Spontaneous and induced mutation rates in di-, tetra-, and hexaploid oats (Avena sp.). Radiation Botany, 15: 279-289.

Coimbra, J. L. M. 2004. Fundamentos do SAS aplicados a experimentação agrícola. UFPel, Pelotas, Brasil, 246pp.

Coimbra, J. L. M.; Carvalho, F. I. F.; Hemp, S.; Oliveira, A. C.; Silva, S.A. 1999b. Divergência genética em feijão prato. Ciência Rural, 29 (2): 427-431.

Coimbra, J. L. M.; Carvalho, F. I. F.; Oliveira, A. C. 2004. Genetic variability in populations of oat induced by agents chemical and physical mutagenics. Crop Breeding and Applied Biotechnology, 4: $48-56$.

Coimbra, J. L. M.; Carvalho, F. I. F.; Oliveira, A. C.; Coimbra, S.; Silva, J. A. G.; Lorencetti, C.; Chocorosqui, V. R. 2005a. Doses de raio gama na cultura da aveia: estatura de planta. Revista Brasileira de Agrociência, 11 (3): 305-308.

Coimbra, J. L. M.; Carvalho, F. I. F.; Oliveira, A. C.; Silva, J. A. G.; Lorencetti, C. 2005b. Comparação entre mutagênicos químico e físico em populações de aveia. Ciência Rural, 35 (1): 46-55.

Coimbra, J. L. M.; Guidolin, A. F.; Carvalho, F. I. F.; Coimbra, S. M. M.; Marchioros, V. S. 1999a. Análise de trilha I: análise do rendimento de grãos e seus componentes. Ciência Rural, 29 (2), 213-218.
Cruz, C. D.; Regazzi, A. J. 2001. Modelos biométricos aplicados ao melhoramento genético. UFV, Viçosa, Brasil, 390pp.

Elias, H. T.; Vidigal, M. C.; Gonela, A.; Vgot, G. A. 2007. Variabilidade genética em germoplasma tradicional de feijão-preto em Santa Catarina. Pesquisa Agropecuária Brasileira, 42 (10): 1443-1449.

Falconer, D. S.; Mackay, T. F. C. 1996. Introduction to quantitative genetics. $4^{\text {th }}$ ed. Longman, London, UK, 463pp.

Gregory, W. C. 1967. Mutation breeding. In: Frey, K. J. (Ed.). Plant breeding. Iowa State University, Ame, USA, p.189-217.

Kopp, M. M.; Coimbra, J. L. M.; Luz, V. K.; Farias, D. R.; Carvalho, F. I. F.; Oliveira, A. C. 2007 Butyric acid tolerance of rice mutant M4 families. Crop Breeding and Applied Biotechnology, 7: 373 380 .

Lins, S. S.; Alves, A. C. 2002. Comportamento de linhagens de feijão-mungo (Vigna radiata L.) em Santa Catarina. Ciência Rural, 32 (4): 553-558.

Maluszynski, M. 1998. Crop germplasm enhancement through mutation techniques. In: Rutger, J. N.; Robinson, J. F. \& Dilday, R. H. (Eds). Proceedings of the International Symposium on Rice Germplasm Evaluation and Enhancement. AAES Special Reports, Arkansas, USA, p.74-82.

Predieri, S. 2001. Mutation induction and tissue culture in improving fruits. Plant Cell, Tissue and Organ Culture, 64 (2 3): $185-210$

Rencher, A. C. 2002. Methods of multivariate analysis. WileyInterscience Publication, New Work, USA, 740pp.

Ribeiro, N. D.; Cargnelutti Filho, A.; Jost, E.; Poersch, N. L.; Trentin, M. 2004. Alterações em caracteres agromorfológicos em função da densidade de plantas em cultivares de feijão. Revista Brasileira de Agrociência, 10 (2): 167-173.

SAS INSTITUTE INC. 2007. SAS ${ }^{\circledR}$ 9.1.3 (TS1M3) for Windows Microsoft. SAS Institute Inc, Cary, USA, 212pp.

Shimada, M. M.; Arf, M.; Sá, M. E. 2000. Componentes do rendimento e desenvolvimento do feijoeiro de porte ereto sob diferentes densidades populacionais. Bragantia, 59 (2): 181-187.

Silva, C. C.; Bevitore, R. 1994. Colheita e beneficiamento de feijão. Informe Agropecuário Belo Horizonte, 17 (178): 54-63.

Sudré, C. P.; Rodrigues, R.; Riva, E. M.; Karasawa, M.; Amaral Junior, A. T. 2005. Divergência genética entre acessos de pimenta e pimentão utilizando técnicas multivariadas. Horticultura Brasileira, 23 (1): 22-27.

Tulmann Neto, A.; Latado, R. R. 1997. Indução de mutação in vivo, no melhoramento de crisântemo (Dendrathema Grandiflora Tzvelev) cv. Repin rosa. Pesquisa Agropecuária Brasileira, 32 (11): $1153-1158$. 